\title{
China has faster pace than Japan in population aging in next 25 years
}

\author{
Rong Chen ${ }^{1}$, Ping $\mathrm{Xu}^{2}$, Peipei Song ${ }^{1,3}$, Meifeng Wang ${ }^{1}$, Jiangjiang He $\mathrm{H}^{1,4, *}$ \\ ${ }^{1}$ Shanghai Health Development Research Center (Shanghai Medical Information Center), Shanghai, China; \\ ${ }^{2}$ Department of Gerontology, University of Massachusetts Boston, MA, USA; \\ ${ }^{3}$ The Institute for Global Health Policy Research, National Center for Global Health and Medicine, Tokyo, Japan; \\ ${ }^{4}$ School of Public Health, Fudan University, Shanghai, China.
}

\begin{abstract}
Summary The aging of a population structure is an inevitable path of demographic transition, as an inescapable result of decline in fertility rate and extension in life expectancy. Although demographic transition occurred earlier in Japan than in China, the two countries had similar patterns, both of which took a much shorter period of time than Western countries to complete demographic transition, as well as have been aging at a rapid speed that has rarely been seen in the world. Japan has the highest level of population aging in the world, and China has been experiencing a very fast pace of the population aging process and has the largest older population. Drawing upon data from World Population Prospects (2019), this paper compares changes in population aging in both China and Japan. Findings show that Japan's aging process is $\mathbf{3 0}$ years ahead of China, but China has been changing in a similar way as Japan. To be specific, both countries experienced four phases of the population aging process: accelerated development period, rapid development period, slow down period and high-level maintained period. In addition, both countries had a quick growing rate of population aging. It will take China 23 years and $\mathbf{1 0}$ years respectively for the aging rate increasing from $7 \%$ to $14 \%$ and then to $20 \%$, while Japan took 24 and 11 years respectively, which is much shorter than developed countries in the West. Furthermore, China has a faster pace than Japan in population aging in the next 25 years. We found that from 2019-2044, China's aging rate, elderly dependency ratio, oldest-old coefficient and median age of population will increase 13.24 percent points, 24.21 percent points, 8.33 percent points, and 8.47 years, while the four indicators of Japan will increase 8.38 percent points, 22.52 percent points, 8.29 percent points, and 6.20 years, respectively.
\end{abstract}

Keywords: Population aging, China, Japan, comparative study

\section{Introduction}

Population aging is a dynamic process of increasing proportion of older adults in the total population, which is a result of low fertility rate and high life expectancy (1). The United Nations and the World Health Organization defines "aging society" as older

Released online in J-STAGE as advance publication August 21, 2019.

*Address correspondence to:

Jiangjiang He, Shanghai Health Development Research Center (Shanghai Medical Information Center), No.1477, Beijing (W) Road, Jing'an District, Shanghai 200040, China. E-mail: hejiangjiang@shdrc.org population aged 65 years and over taking up 7\% of the total population. When the percentage reaches $14 \%$, it is called "aged society", where "super-aged society" refers to more than $20 \%$ of the population is over 65 (2). Population aging is now a global trend. World Population Prospects (2019) (hereafter as WPP2019) (3) reported that since 2002, the proportion of older adults aged 65 and over in the global population has exceeded $7 \%$. The rate is expected to reach $14.14 \%$ in $2040,20.04 \%$ in 2079 , and $22.59 \%$ by the end of this century. The population aging process in Asian countries draws special attention due to its large total population. According to WPP2019, the proportion of older adults aged 65 and over in Asia reached 7.11\% in 2013, and is predicted to exceed $14 \%$ and $20 \%$ in 2036 
and 2056 respectively (will be $14.10 \%$ and $20.13 \%$, respectively). In particular, countries and regions in East Asia have entered into "aging society" in as early as 1996. They are expected to become "aged society" in 2022, and become "super-aged society" in 11 years (in 2033) (Figure 1).

China and Japan are the most important countries in East Asia, and share similar culture as well due to historical reasons. Although demographic transition in Japan happened earlier than in China, the two countries had similar patterns, both of which took a much shorter period of time than Western developed countries to complete demographic transition (4). Japan is the first country in Asia to enter into aging society with a rapid process of population aging, and it still has the highest level of population aging in the world $(3,5-7)$. China is about 30 years later than Japan entering into aging society. However, China has been experiencing a very fast pace of the population aging process (8), and it will be faster than Japan is the coming period (9)

\section{A Comparative study of the population aging in China and Japan}

\subsection{Comparison of aging process in the two countries after entering into "aging society"}

It is generally accepted that Japan entered into "aging society" in 1970 (10), and China entered into "aging society" in 2000 (11). Japan was 30 years ahead of China. The data used in WPP2019 is slightly different from the domestic statistics of the two countries. WPP2019 (3) shows that Japan's aging rate was 6.88\% in 1970 , and $7.05 \%$ in 1971 , China's aging rate reached $6.81 \%$ in $2000,6.94 \%$ in 2001 and $7.08 \%$ in 2002 . Therefore, according to WPP2019, the two countries entered into "aging society" in 1971 and 2002, respectively. In order to compare the patterns and future trend of population aging between the two countries, and with other countries and regions, this paper uses WPP2019 data. This section compares the speed and process of population aging between the two countries after the year when both entered into "aging society".

First of all, we compared the speed of population aging in China and Japan by measuring how long it takes for the two countries to become "aged society" from "aging society"; and to become "super-aged society" from "aged society", respectively. China is predicted to enter into "aged society" in 2025, and become "superaged society" in 2035. It will take 23 years for China to complete the process from an "aging society" to an "aged society", and 10 years from an "aged society" to "superaged society". Japan has already entered into "aged society" and "super-aged society" in 1995 and 2006, respectively. It took 24 years and 11 years for Japan to complete these two processes. China and Japan are both aging at a much faster rate (Figure 1).

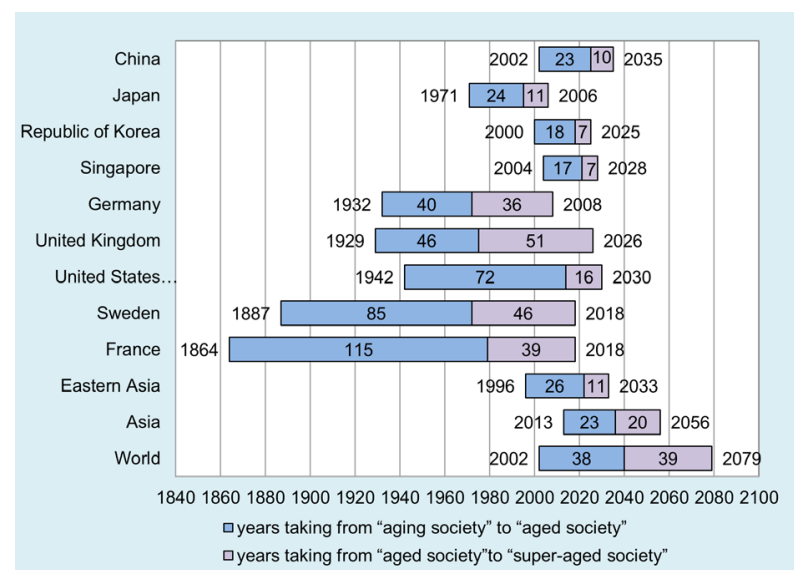

Figure 1. The year and time taken from "aging society" to "aged society", and to "super-aged society" in China, Japan, and other countries/regions. Data sources: The data before 1950 are from the 2018 edition of the white paper of elderly society (10), and the data during 1950-2100 are from WPP2019.

In contrast, it took western developed countries longer to complete these two processes. For instance, France took 115 and 39 years, Sweden took 85 and 46 years, and Germany took 40 and 36 years. The United States of America and the United Kingdom took 72 years and 46 years to complete the process from $7 \%$ to $14 \%$, respectively. The United States of America entered "aged society" in 2014 and is predicted to become "super-aged society" in 2030. It will take 16 years. Also, The United Kingdom has already entered "aged society" in 1975 and is predicted to become "super-aged society" in 2026.

We further analyzed the process of population aging during the 100 years since the two countries entered into "aging society". The time span of WPP2019 data is 1950-2100. We compared the changes of aging rate between 1971-2069 in Japan and 2002-2100 in China. i) The first stage: the first 16 years of entering into "aging society" (corresponding to the data in China from 2002 to 2017 and Japan from 1971 to 1986), the level of aging in China is close to, but slightly lower than of that in Japan. At this stage, both countries aged fast. ii) The second stage: 26 years later (corresponding to China's data in 2018-2044 and Japan's data in 1987-2013), China's aging level is close, but slightly higher than Japan's. At this stage, the aging rate of the two countries is faster than that of the first stage. China's aging rate is predicted to rise from $10.92 \%$ in 2018 to $24.71 \%$ in 2044, and Japan's aging rate rose from $10.71 \%$ in 1987 to $24.63 \%$ in 2013 . iii) The third stage: for the remaining 56 years (corresponding to the data of 2045 2100 in China and 2014-2069 in Japan), China's aging level is lower than that of Japan. Especially after 55 years entering into "aging society", Japan's aging rate is significantly higher than that of China. At this stage, the speed of population aging in China is generally slower than that of Japan. China's speed of aging is predicted 
to slow down in 55 years after entering into "aging society", and the aging rate will reach $30 \%$. Since then, China's aging level will get into a plateau period, maintaining at a level of $31 \%$. The speed of aging in Japan might slow down in 70 years after stepping into "aging society". About 80 years later, Japan's aging process is predicted to reach a plateau period, and the level of aging basically will maintain at $38 \%$. Overall, the two countries both experience the acceleration period, the very rapid period, the slowdown period and the high level platform period of aging during one hundred years after entering into "aging society".

\subsection{China has a faster pace in population aging than Japan in the next 25 years}

The year 2018 is the time when the process of population aging in China turns from an accelerated development period to a rapid development period. And China will be experiencing the fastest speed of population aging in the next 25 years. In the above section, we have compared the aging rate in China and Japan in the same period of time when both entered

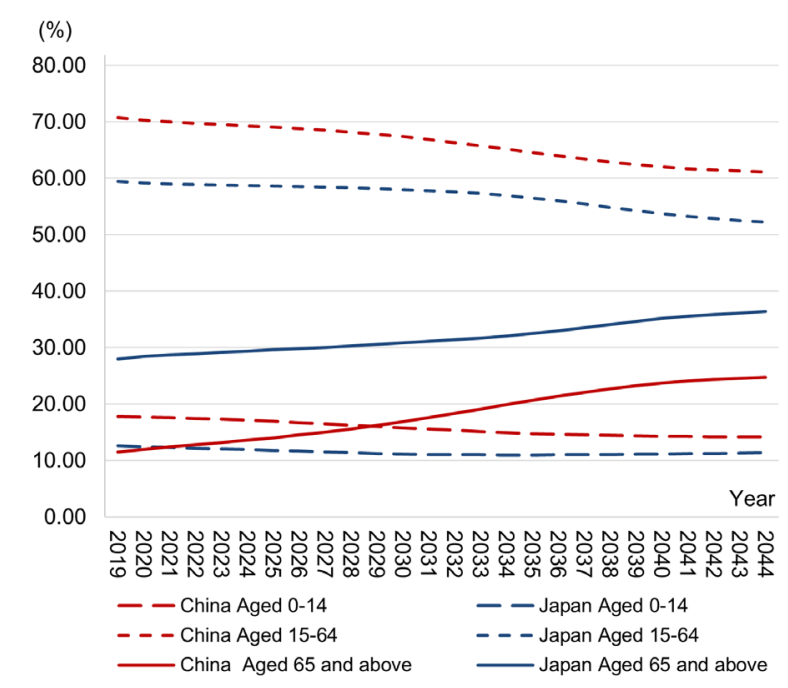

Figure 2. Population age structure changes in China and Japan 2019-2044. into aging society. It was found that the aging rate was slightly higher in China than that in Japan during this rapid development period. In this section, we will compare the aging process between China and Japan over the next 25 years.

Figure 2 presents the changes in age composition in China and Japan from 2019 to 2044. The proportion of children aged 0-14 years in China is higher than that in Japan, however, the rate will decrease faster in China than that in Japan, resulting in a narrower gap between these two countries. The proportion of working-age population aged 15-64 in both countries is declining. Although this proportion in China has been greater in China than that in Japan, the decline rate is larger than that in Japan as well. Moreover, the proportion of older population aged 65 and over in both countries is increasing, and China has a more rapid pace of aging than that in Japan. All of these numbers demonstrate that China's population aging process will be faster than Japan's in the next 25 years.

In addition to the aging rate, certain other indicators have also been commonly used to measure the process of population aging, including the elderly dependency ratio (refers to the ratio of older dependents (people aged 65 and above) to the working-age population (those aged 15-64)), the oldest-old coefficient (refers to the proportion of people aged 80 and over in the population of people aged 65 and over), and the median age of total population $(6,12-13)$. Table 1 shows the aging process of China and Japan between 2019 and 2044 using these indicators. To be specific, in the next 25 years, China's aging rate will increase from $11.47 \%$ to $24.71 \%$, an increase of 13.24 percent points; where Japan's aging rate will increase from $28.00 \%$ to $36.38 \%$, an increase of 8.38 percent points. Regarding the elderly dependency ratio, China will raise from $16.22 \%$ to $40.43 \%$, an increase of 24.21 percent points; where Japan will raise from $47.12 \%$ to $69.64 \%$, an increase of 22.52 percent points. With respect to the proportion of the elderly aged 80 and above in the elderly, China will climb from $15.90 \%$ to $24.23 \%$, an increase of 8.33 percent points; while Japan will increase from $31.02 \%$

Table 1. Comparison on Selected Indicators of Population Aging in China and Japan 2019-2044

\begin{tabular}{|c|c|c|c|c|c|c|c|c|}
\hline \multirow{2}{*}{ Year } & \multicolumn{2}{|c|}{ Aging rate } & \multicolumn{2}{|c|}{ Elderly dependency ratio } & \multicolumn{2}{|c|}{ Oldest-old coefficient } & \multicolumn{2}{|c|}{ Median age of the total population } \\
\hline & China & Japan & China & Japan & China & Japan & China & Japan \\
\hline 2019 & 11.47 & 28.00 & 16.22 & 47.12 & 15.90 & 31.02 & - & - \\
\hline 2020 & 11.97 & 28.40 & 17.02 & 48.01 & 15.45 & 31.61 & 38.42 & 48.36 \\
\hline 2025 & 14.03 & 29.63 & 20.32 & 50.57 & 15.40 & 35.64 & 40.23 & 50.48 \\
\hline 2030 & 16.87 & 30.87 & 25.04 & 53.22 & 16.70 & 41.50 & 42.65 & 52.07 \\
\hline 2035 & 20.68 & 32.51 & 32.02 & 57.52 & 19.84 & 42.82 & 44.99 & 53.28 \\
\hline 2040 & 23.73 & 35.17 & 38.27 & 65.52 & 20.92 & 40.00 & 46.32 & 54.12 \\
\hline 2044 & 24.71 & 36.38 & 40.43 & 69.64 & 24.23 & 39.31 & 47.16 & 54.56 \\
\hline Change & 13.24 & 8.38 & 24.21 & 22.52 & 8.33 & 8.29 & 8.74 & 6.20 \\
\hline
\end{tabular}

Data sources: WPP2019.

Note: Due to the median age of total population in WPP2019 are separated by 5 years, the median age of total population of 2009 in Table1 is vacant, and the median age of total population of 2044 in Table1 is the data of 2045 in WPP2019 database. 
to $39.31 \%$, an increase of 8.29 percent points. Lastly, the median age of total population in China will rise from 38.42 years in 2020 to 47.16 years, an increase of 8.74 years, and the media age of total population in Japan will rise from 48.36 years to 54.26 years, an increase of 6.20 years. In sum, these four indicators show that the population aging process in China will be quicker than that in Japan in about 25 years.

\subsection{Reasons for population aging in China and Japan}

Population aging process is earlier in Japan than that in China, however, the common feature in both countries is the vast rapid speed (14). The aging of population structure is an inevitable path of demographic transition, as the inescapable result of decline in fertility rate and extension in life expectancy (15).

Low fertility rate has been considered as the most important determinant for population aging (16). China's total fertility rate (the number of children born to each woman in her lifetime) was 6 in 1950s and 1960s. Due to the development of social economy and the implementation of the family planning policy, the total fertility rate has dropped significantly in 1970s (17). It dropped to 3 at the end of $1970 \mathrm{~s}$, to 2.5 in $1980 \mathrm{~s}$, below the threshold of 2.1 in $1990 \mathrm{~s}$, and has been below 2.1 for three decades since then. It reached an historical low of 1.6 in 2000. The estimation in WPP2019 should take into account the impact of family planning policy on fertility in China, therefore, the birth rate was set to 1.70 1.75 between 2020-2050. Japan is the first nonWestern country that was found to track the typical transition pattern (18). The total fertility rate has fallen much earlier in Japan than that in China. It has dropped to around 2.5 in $1950 \mathrm{~s}$, to about 2 in $1960 \mathrm{~s}$, and slightly rose to 2.13 in $1970-1975$, then dropped back to 1.83 in 1975-1980. Japan's total fertility rate continued to decline in 1980s and in 1990s, and reached the lowest point of 1.3 during 2000-2005. Though it has increased a bit since 2005, the average is still lower than 1.4. The predication in WPP2019 should consider the effect of policy in encouraging giving birth in Japan, and set the total fertility rate in Japan as a slow increase in 20202050, reaching 1.55 in 2050 (Figure 3). In sum, China's fertility rate dropped sharply in the second half of the 20 th century, which was far greater than Japan's. While in the first half of the 21 st century, the two countries' fertility rates did not change much. China was relatively higher than Japan, but was still below the replacement level.

Another critical factor for population aging is the decline of mortality, especially among older adults (16). In Japan, since low fertility rates have been maintained for a long time, the more prominent reason for the growing number of aging population is low death rate of the elderly (18). In the second half of last century, life expectancy has greatly increased in both China and

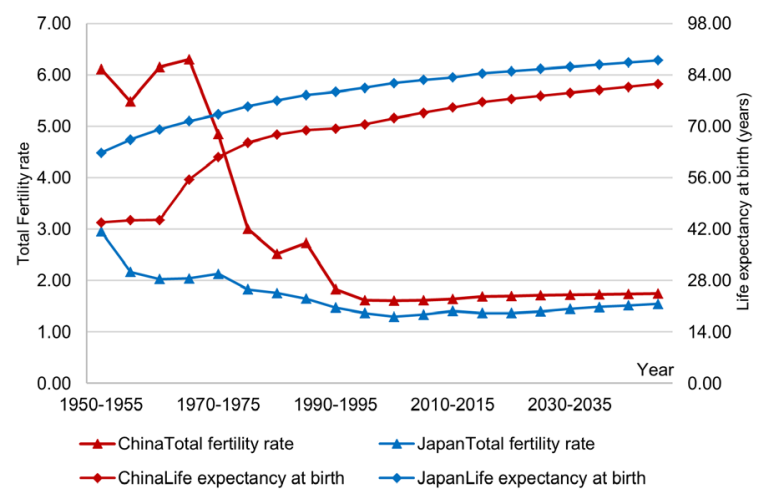

Figure 3. Fertility decline and life expectancy increase in China and Japan (1950-2050). Data sources: WPP2019.

Japan. China's average life expectancy has improved from 43.83 to 70.58 , an increase of 26.75 years; Japan's average has advanced from 62.80 to 80.51 , an increase of 17.71 years. During the same time period, the world's average life expectancy has increased from 46.96 to 65.63 , an increase of 18.67 years, and Asia's has extended from 42.30 to 66.55 , an increase of 24.25 years. We can see that China has the greatest growth rate in terms of life expectancy. Japan has already had the highest life expectancy, and its growth rate is not as great as China's. However, Japan's life expectancy is still about 10 years higher than China's at the end of 1990s. Since 2000, although the two countries' life expectancies continued to grow, the gap between them became narrower, reaching 76.62 years and 84.43 years in China and Japan respectively during 2015-2020. It is estimated by WPP2019 that life expectancy will reach 81.52 years and 87.94 years in China and Japan respectively by 2050 . Similarly, the world's average life expectancy at birth will increase from 67.05 to 76.77 years during the same period, an increase of 8.44 years. Asian's average life expectancy at birth will increase from 68.33 to 77.89 , an increase of 9.56 years. Overall, China has a much faster improvement rate in life expectancy than that of Japan, worldwide and Asia. China's mortality rate has declined more obviously than Japan's; however, China's life expectancy has always been lower than Japan's (Figure 3).

\section{Conclusion}

Due to declining fertility rate and extended life expectancy, China and Japan have experienced and will continue to encounter a rapid population aging process. Japan is about 30 years earlier than China entering into aging society, and has a higher level of aging than that of China as well; nevertheless, China will run into a faster pace than Japan in aging process in the coming 25 years. Population aging and its consequences raise challenges and concerns for society, family, and older adults. Compared to China, Japan has more advanced 
social-economic development and policies and strategies to deal with population aging, as well as has greater capacity for coping with challenges. China has a lower level of population aging than that of Japan, however, the number of older adults in China is several times more than that of Japan (4.6 times in 2019 and 8.8 times in 2044). Therefore, China will face even more severe issues and challenges because of its rapid process of population aging and continued increase in the size of older population over a long period of time. The outpaced growth of aging population over that of economic development and social security system in China may put tremendous pressures on older individuals, their families, as well as on society (19-21).

\section{Acknowledgements}

This work was supported by the National Natural Science Foundation of China 71490734 (to Rong Chen and Meifeng Wang).

\section{References}

1. United Nations. Population ageing and sustainable development. Population Facts. 2014; 4:1-4.

2. Wang Z, Sun T, Li G. Regional differences and evolutions of population aging in China. Population Research. 2013; 1:66-77. (in Chinese)

3. United Nations, Department of Economic and Social Affairs, Population Division (2019). World Population Prospects 2019, Online Edition. https://population.un.org/ wpp/Download/Standard/Population. (accessed June 5, 2019).

4. Wang G. The comparison of population aging among older-old in China with in Japan. Population \& Economics. 2003; 2:48-52, 42 (in Chinese)

5. Wang L. An international comparative study on Japan's aging population. Japan Studies. 2011; 25:41-50. (in Chinese)

6. Song Y. Japan's population aging "overspeed" and overseas immigration policy. Journal of foreign studies. 2019; 1:24-30. (in Chinese)

7. Wang Y, Zhang J. The experiences of Japan and South Korea on countermeasures against population aging and its references. Population Journal. 2015; 6:76-84. (in Chinese)

8. The Drafting Group of General Report. The general research report of Chinese strategy for dealing with population aging. Scientific Research on Aging. 2015; 3:4-38. (in Chinese)

9. Masaaki Shirakawa. Stimulating economic vitality under an aging and few-children society: Japan's experience and its implications to China. http://www.cf40.org.cn/ plus/view.php?aid=13538. (accessed June 6, 2019) (in Chinese)

10. Ding Y. The latest situation, social impact and related social policies of Japan's aging - interpretation of the 2018 edition of the white paper of elderly society. Japan Studies. 2019; 1:27-37. (in Chinese)

11. National Bureau of Statistics of China. China Statistical Yearbook 2018. http://www.stats.gov.cn/tjsj/ndsj/2018/ indexch.htm. (accessed June 8, 2019).

12. Liu C. A comparative study of the population aging in China and Japan. South China Population. 2003; 2:24-29. (in Chinese)

13. Wang G. 70 years of China: The changes of population age structure and the trend of population aging. 2019; 3:215. (in Chinese)

14. Qi L, Zhuang Y. Starting in China, Mature in Japan - To learn the experience of Japan dealing with aging society. Future and Development. 2014; 38:40-45. (in Chinese)

15. Lee R. The demographic transition: Three centuries of fundamental change. The Journal of Economic Perspectives. 2003; 17:167-190.

16. Mu G. A comparative study of population aging in China, Japan and South Korea. Journal of China Executive Leadership Academy Yan' an. 2012; 5:108-114, 55. (in Chinese)

17. Chen R, Xu P, Li F, Song P. Internal migration and regional differences of population aging: An empirical study of 287 cities in China. Biosci Trends. 2018; 12:132141.

18. Shimizutani S. Population aging in postwar Japan: Processes and prospects. Asia-Pacific Review, 2015; 22:53-76.

19. Du P, Yang H. "Ageing before Affluence" is a central feature of population ageing in China at the present stage. Population Research. 2006; 6:28-36. (in Chinese)

20. Cai F. "Ageing before Affluence" and China's sustainable economic growth. International Economic Review. 2012; 1:82-95.

21. Zhu H. Adult children's characteristics and intergenerational financial transfers in urban China. Chinese Journal of Sociology. 2016; 2:75-94.

(Received June 26, Revised August 12, 2019; Accepted August 18, 2019) 